\title{
The association between dietary energy intake and the risk of mortality in maintenance haemodialysis patients: a multi-centre prospective cohort study
}

\author{
Yaya Yang ${ }^{1}$, Xianhui Qin ${ }^{1}$, Yan $\mathrm{Li}^{1}$, Zihan $\mathrm{Lei}^{1}$, Yumin $\mathrm{Li}^{1}$, Shenglin Yang ${ }^{1}$, Youbao $\mathrm{Li}^{1}$, Yaozhong Kong ${ }^{2}$, \\ Yongxin $\mathrm{Lu}^{3}$, Yanhong Zhao ${ }^{3}$, Qijun Wan ${ }^{4}$, Qi Wang ${ }^{5}$, Sheng Huang ${ }^{6}$, Yan Liu ${ }^{7}$, Aiqun Liu ${ }^{8}$, Fanna Liu?, \\ Fanfan $\mathrm{Hou}^{1}$ and Min Liang ${ }^{1 *}$ \\ ${ }^{1}$ National Clinical Research Center for Kidney Disease, State Key Laboratory of Organ Failure Research, Renal Division, \\ Nanfang Hospital, Southern Medical University, Guangzhou 510515, People's Republic of China \\ ${ }^{2}$ The First People's Hospital of Foshan, Foshan 528000, People's Republic of China \\ ${ }^{3}$ People's Hospital of Yuxi City, Yuxi 653100, People's Republic of China \\ ${ }^{4}$ The Second People's Hospital of Shenzhen, Shenzhen 518000, People's Republic of China \\ ${ }^{5}$ Huadu District People's Hospital of Guangzhou, Guangzhou 510515, People's Republic of China \\ ${ }^{6}$ Nanhai District People's Hospital of Foshan, Foshan 528000, People's Republic of China \\ ${ }^{7}$ Guangzhou Red Cross Hospital, Guangzhou 510515, People's Republic of China \\ ${ }^{8}$ The Third Affiliated Hospital of Southern Medical University, Guangzhou 510515, People's Republic of China \\ ${ }^{9}$ Guangzhou Overseas Chinese Hospital, Guangzhou 510515, People's Republic of China
}

(Submitted 19 June 2019 - Final revision received 14 October 2019 - Accepted 30 October 2019 - First published online 8 November 2019)

\section{Abstract}

Maintenance haemodialysis (MHD) is the use of a machine to filter wastes, salts and fluid from blood for at least 3 months to prolong the life of patients with advanced kidney failure. Although low dietary energy intake (DEI) has been observed in MHD patients, few studies have related DEI to the risk of mortality. To explore this relationship, a study included 1039 MHD patients from eight centres was conducted. DEI was assessed by three 24-h diet recalls and was normalised to ideal body weight (IBW). All-cause mortality and CVD mortality were the primary and secondary outcomes, respectively. During a median follow-up of 28 months, a U-shaped relationship was observed between DEI and allcause or CVD mortality. The risk of all-cause mortality decreased significantly with the increase of DEI in participants with DEI $<167 \cdot 4 \mathrm{~kJ} / \mathrm{kg}$ IBW per d (hazard ratio (HR) $0.98 ; 95 \% \mathrm{CI} 0.96,1 \cdot 00$ ) and increased significantly with the increase of DEI in those with DEI $\geq 167 \cdot 4 \mathrm{~kJ} / \mathrm{kg}$ IBW per $\mathrm{d}$ (HR 1.12; $95 \%$ CI 1.04, 1.20). Similarly, the risk of CVD mortality decreased with the increase of DEI in participants with DEI $<152 \cdot 7 \mathrm{~kJ} / \mathrm{kg}$ IBW per d (HR 0.96; $95 \%$ CI 0.93, 0.99) and increased with the increase of DEI in participants with DEI $\geq 152.7 \mathrm{~kJ} / \mathrm{kg} \mathrm{IBW}$ per d (HR $1.11 ; 95 \% \mathrm{CI} 1.04$, 1.18). In summary, there was a U-shaped association between DEI and all-cause or CVD mortality, with a turning point at about $167 \cdot 4$ and $152 \cdot 7 \mathrm{~kJ} / \mathrm{kg}$ IBW per $\mathrm{d}$, respectively, in MHD patients.

Key words: All-cause mortality: CVD mortality: Dietary energy intake: Maintenance haemodialysis patients

Patients with end-stage renal disease often have extensive CVD, with estimates of annual mortality as high as $20 \%{ }^{(1)}$. This ongoing high mortality rate serves as an incentive to seek and establish more preventive strategies for dialysis-dependent patients.

Maintenance haemodialysis (MHD) is the use of a machine to filter wastes, salts and fluid from blood for at least 3 months to prolong the life of patients with advanced kidney failure. Several previous studies have found that MHD patients tend to have low dietary energy intake (DEI) and to be underweight $^{(2-5)}$. Inadequate energy intake is a frequent and important cause of protein-energy wasting, which closely related to major adverse clinical outcomes in MHD patients ${ }^{(6,7)}$. Hence, ensuring the optimal amount of energy intake is very important to improve the clinical outcomes of MHD patients. A metabolic balance study on six MHD patients suggested that a mean energy intake of $146.4 \mathrm{~kJ} / \mathrm{kg}$ per d was necessary to maintain both a neutral nitrogen balance and an unchanged body composition $^{(8)}$. Mainly based on this study, the European Best

Abbreviations: ABW, actual body weight; CRP, C-reactive protein; DEI, dietary energy intake; IBW, ideal body weight; MHD, maintenance haemodialysis; TC, total cholesterol.

* Corresponding author: Min Liang, email nfyylm@163.com 
Practice Guidelines on nutrition recommend a DEI of 125.5$167.4 \mathrm{~kJ} / \mathrm{kg}$ of ideal body weight (IBW) per d in clinically stable MHD patients ${ }^{(9)}$. The guidelines from the Kidney Disease Outcome Quality Initiative recommend a daily DEI of $146.4 \mathrm{~kJ} / \mathrm{kg}$ body weight per d for MHD patients who are $<60$ years of age and a DEI of $125 \cdot 5-146.4 \mathrm{~kJ} / \mathrm{kg}$ body weight per $d$ for those 60 years of age or older ${ }^{(4)}$. And, the International Society of Renal Nutrition and Metabolism consensus indicates that the minimum energy requirements for MHD patients are $125 \cdot 5-146 \cdot 4 \mathrm{~kJ} / \mathrm{kg}$ of IBW per $\mathrm{d}$ based on the physical activity level ${ }^{(6)}$.

However, few epidemiological studies have prospectively examined the association between DEI and risk of mortality in MHD patients, and the optimal energy intake for prevention of mortality in such patients is still unknown. Estimation of DEI can only be done by monitoring intake. The most common methods for estimating dietary intake are FFQ, food intake records and 24-h dietary recalls ${ }^{(10,11)}$. Given evidence from biomarker-based validation, the 24-h dietary recalls capture dietary intake with less bias than do $\mathrm{FFQ}^{(12,13)}$. Moreover, the US Department of Agriculture five-step multiple-pass method for dietary recall has been validated by a lot of previous studies $^{(14-17)}$. Therefore, we make the assumption that the 24-h recalls used in the present study reflected the DEI because of earlier validations. Our purpose was to explore the relationship of DEI with all-cause and CVD mortality and to examine any possible effect that modifies among MHD patients.

\section{Methods \\ Study design and participants}

The present study was a multi-centre, prospective cohort study conducted from January 2014 to December 2015, in eight outpatient dialysis centres (including Nanfang Hospital, the First People's Hospital of Foshan, Huadu District People's Hospital of Guangzhou, Guangzhou Red Cross Hospital, Guangzhou Overseas Chinese Hospital, the Third Affiliated Hospital of Southern Medical University, Nanhai District People's Hospital of Foshan and the Second People's Hospital of Shenzhen) in Guangdong province in China. Eligible participants were males and females aged more than 18 years who had received maintenance dialysis for at least 3 months and had a normal oral intake. We excluded those who had hyperthyroidism, acute infection, liver cirrhosis, multiple organ failure, serious gastrointestinal disease, cognitive disorder and advanced malignant tumour.

Participants were followed up at each routine dialysis visit where vital signs and possible endpoint events were documented by trained research staff and physicians.

The study was approved by the Medical Ethics Committee of Nanfang Hospital and all the participants signed an informed consent.

\section{Data collection and measurements}

Baseline data were collected by trained research staff according to standard operating procedures. Interviews were conducted on each participant using a standardised questionnaire designed specifically for the present study.

Diabetes mellitus was defined as having a medical history of diabetes, or undergoing glucose-lowing therapy, including insulin or oral hypoglycaemic agents. Patients who reported antihypertensive drugs use or had a medical history of hypertension were defined as having hypertension. The history of CVD was defined as history of angina, congestive heart failure, transient ischemic attack, history of myocardial infarction or cerebrovascular accident and peripheral arterial disease. The question about physical activity was phrased as follows, 'How do you describe your daily physical activity level?' and a choice of three responses: low, moderate and high was provided ${ }^{(18,19)}$.

Anthropometric measures including weight and height were obtained during the physical examination. All measurements were conducted post-dialysis when the patient was at dry weight. BMI was calculated as weight/height squared $\left(\mathrm{kg} / \mathrm{m}^{2}\right)$.

Dietary intake was assessed by trained interviewers using the automated multiple-pass method where 24-h diet recalls were administered on $3 \mathrm{~d}$ (including one dialysis day and two nondialysis days) within 1 week. The 24 -h diet recalls are relatively quick assessment modalities to obtain the most recent information about food intake and are widely used in epidemiological studies $^{(10)}$. Briefly, the automated multiple-pass method was developed by the US Department of Agriculture and utilises a five-step, multiple-pass, interviewer-administered, computerised process for obtaining diet recalls. The automated multiple-pass method consists of five following steps: (a) the quick list, which is an uninterrupted listing by the subject of foods and beverages consumed; (b) the forgotten foods list, which queries the subject on categories of foods that have been documented as frequently forgotten; (c) a time and occasion at which foods were consumed; (d) the detail cycle, which elicits descriptions of foods and amounts eaten aided by the use of the Food Model Booklet; and finally (e) the final probe review ${ }^{(12,17)}$. The energy intake of all food and drink items was sourced using a computer-aided dietary software (China software version 2.0), in which nutrient models were based on the Chinese Food Composition Table developed by the Chinese Center for Disease Control and Prevention, 2009.

DEI was expressed in three units of measure: actual energy intake in $\mathrm{kJ} / \mathrm{d}$, energy intake normalised to actual body weight (ABW) in $\mathrm{kJ} / \mathrm{kg} \mathrm{ABW}$ per $\mathrm{d}$ and energy intake normalised to IBW in $\mathrm{kJ} / \mathrm{kg}$ IBW per $\mathrm{d}$. As guidelines recommended, we used IBW instead of ABW, since normalising energy intake to ABW would result in erroneously high- or low-energy requirements in overweight or underweight patients ${ }^{(6,9)}$. In the main analysis of the present study, IBW was calculated using improved Broca formula adapted for Asian populations: IBW $=($ height $(\mathrm{cm})-$ $100) \times 0.9(\mathrm{~kg})$ for males and (height $(\mathrm{cm})-100) \times 0.9-2.5$ $(\mathrm{kg})$ for females ${ }^{(20,21)}$. Moreover, IBW was also calculated by multiplying an ideal BMI of $22 \mathrm{~kg} / \mathrm{m}^{2}$ with a person's actual height $(\mathrm{m})$ squared $^{(20,22)}$ in the sensitivity analysis.

Blood samples of all participants were obtained from each subject prior to the haemodialysis session at baseline. Serum lipids, albumin, $\mathrm{Ca}$, phosphate levels and total $\mathrm{CO}_{2}$ were measured using automatic clinical analysers following the same standard protocol at each local dialysis centre. 


\section{Study outcomes}

All-cause mortality was the primary outcome in this analysis and included death due to any reason. The secondary outcome was death from CVD, which included sudden cardiac death, myocardial infarction, heart failure, stroke, cardiovascular haemorrhage and death due to other known vascular causes. Evidence for death included death certificates from hospitals or reports from investigator visits.

\section{Statistical analysis}

We assumed that the annual mortality rate of MHD patients is $20 \%{ }^{(1)}$, the hazard ratio (HR) of the DEI between $<104.6$ and $\geq 104.6 \mathrm{~kJ} / \mathrm{kg}$ IBW per d was about $1.67^{(23)}$, with an $\alpha$ of 0.05 , and 124 MHD patients followed up for 2 years would have a power of $90 \%$.

Baseline characteristics are presented as means and standard deviations for normally distributed continuous variables, medians (Q1-Q3) for skewed continuous variables and frequencies (percentages) for categorical variables. Differences in baseline characteristics according to DEI categories $(<125 \cdot 5$, 125.5$146 \cdot 4,146 \cdot 4-167 \cdot 4$ and $\geq 167 \cdot 4 \mathrm{~kJ} / \mathrm{kg}$ IBW per d) were compared using $\chi^{2}$ tests or ANOVA tests as appropriate.

Cox proportional hazards models were used to estimate the HR and $95 \% \mathrm{CI}$ for the risk of all-cause mortality and CVD mortality associated with DEI, without and with adjustments for dialysis centre, age, sex, smoking, alcohol use, physical activity, BMI, albumin, TAG, total cholesterol (TC), C-reactive protein (CRP), $\mathrm{Ca}$, phosphate, $\mathrm{Hb}$, dialysis vintage, $\mathrm{Kt} / \mathrm{V}$, diabetes, hypertension and history of CVD. We applied two piecewise regression models to examine the threshold effect of DEI on the risk of all-cause mortality or CVD mortality using a smoothing function. The threshold level (turning point) was determined using likelihood-ratio tests and bootstrap re-sampling methods.

In a stratified analysis, possible modifications of the association between DEI and all-cause mortality were assessed for the variables, age (<60 v. $\geq 60$ years), sex, diabetes (yes $v$. no), history of CVD (yes $v$. no), CRP $(<8 v . \geq 8 \mathrm{mg} / \mathrm{l})^{(24)}$, TC $(<5 \cdot 2 v$. $\geq 5 \cdot 2 \mathrm{mmol} / \mathrm{l})^{(25)}$ and BMI $\left(<23 v . \geq 23 \mathrm{~kg} / \mathrm{m}^{2}\right)^{(26)}$ levels at baseline.

A two-tailed $P<0.05$ was considered statistically significant in all analyses. All analyses were performed using Empower (R) (www.empowerstats.com, X\&Y Solutions, Inc.) and $\mathrm{R}$ (http://www.R-project.org).

\section{Results}

\section{Study participants and baseline characteristics}

As illustrated in the flow chart (online Supplementary Fig. S1), 1039 MHD patients were included in the final analyses.

At baseline, 577 (55.5\%), 222 (21.4\%), 154 (14.8\%) and 86 (8.3\%) participants had DEI $<125 \cdot 5,125 \cdot 5$ to $<146 \cdot 4,146 \cdot 4$ to $<167 \cdot 4$ and $\geq 167 \cdot 4 \mathrm{~kJ} / \mathrm{kg}$ IBW per $\mathrm{d}(<30,30-<35,35-<40$ and $\geq 40 \mathrm{kcal} / \mathrm{kg}$ IBW per d), respectively. Mean values of DEI in total population were $6695 \cdot 7$ (sD 1860.2) kJ per $\mathrm{d}$ and $122 \cdot 6$ (sD 33.1) kJ/kg IBW per d, respectively.

Participant characteristics by DEI categories are listed in Table 1. Patients with lower DEI tended to be older, had lower
TC, serum Ca, serum phosphate, CRP, dietary protein intake, and were more likely to be males.

\section{Relationship of dietary energy intake with all-cause and CVD mortality}

Over a median follow-up of 28 months, eighty-four patients underwent kidney transplantation, five patients switched to peritoneal dialysis and fifty-five patients were lost to follow-up. These patients were censored at the last date of follow-up. All-cause and CVD mortality occurred in 230 (22.1\%) and 140 (13.5\%) participants, respectively.

Overall, a U-shaped relationship was observed between DEI and all-cause mortality (Fig. 1(a)). The two piecewise regression models showed that a DEI value of $167.4 \mathrm{~kJ} / \mathrm{kg}$ IBW per $\mathrm{d}$ ( $40 \mathrm{kcal} / \mathrm{kg}$ IBW per d) was a turning point for all-cause mortality after multi-variate adjustment. That is, the risk of all-cause mortality decreased significantly with the increase of DEI in participants with DEI < 167.4 kJ/kg IBW per d (40 kcal/kg IBW per d) (HR 0.98; $95 \%$ CI $0.96,1.00 ; P=0.027)$, but increased significantly with the increase of DEI in participants with DEI $\geq 167.4 \mathrm{~kJ} / \mathrm{kg}$ IBW per $\mathrm{d}$ ( $40 \mathrm{kcal} / \mathrm{kg} \mathrm{IBW}$ per d) (HR 1.12; $95 \%$ CI 1.04, 1.20; $P=0.002$ ) (Table 2). Consistently, when compared with participants with DEI of 146.4 to $<167.4 \mathrm{~kJ} / \mathrm{kg}$ IBW per d $(35$ to $<40 \mathrm{kcal} / \mathrm{kg}$ IBW per d), a significantly higher risk of all-cause mortality was observed in those with DEI $<125.5 \mathrm{~kJ} / \mathrm{kg}$ IBW per d $(30 \mathrm{kcal} / \mathrm{kg}$ IBW per d) (HR 1.85; $95 \%$ CI 1.20, 2.85), and a higher but insignificant risk of all-cause mortality was also found in participants with DEI $\geq 167.4 \mathrm{~kJ} / \mathrm{kg}$ IBW per d ( $40 \mathrm{kcal} / \mathrm{kg}$ IBW per d) (HR 1.83; 95\% CI 0.99, 3.40) (Table 3).

Similarly, a U-shaped association was also found between DEI and CVD mortality (Fig. 1(b)). The two piecewise regression models showed that a DEI value of $152.7 \mathrm{~kJ} / \mathrm{kg}$ IBW per $\mathrm{d}$ $(36.5 \mathrm{kcal} / \mathrm{kg}$ IBW per d) was a turning point for CVD mortality after multi-variate adjustment. The risk of CVD mortality decreased significantly with the increase of DEI in participants with DEI $<152.7 \mathrm{~kJ} / \mathrm{kg}$ IBW per d $(36.5 \mathrm{kcal} / \mathrm{kg}$ IBW per d) (HR 0.96; $95 \%$ CI 0.93, 0.99; $P=0.006$ ) but increased significantly with the increase of DEI in participants with DEI $\geq 152.7 \mathrm{~kJ} / \mathrm{kg}$ IBW per d (36.5 kcal/kg IBW per d) (HR 1.11; $95 \%$ CI 1.04 , $1 \cdot 18 ; P=0 \cdot 002$ ) (Table 2). Consistently, when compared with participants with DEI of $146 \cdot 4$ to $<167 \cdot 4 \mathrm{~kJ} / \mathrm{kg} \mathrm{IBW}$ per d ( 35 to $<40 \mathrm{kcal} / \mathrm{kg}$ IBW per d), a significantly higher risk of CVD mortality was observed in those with DEI $<125.5 \mathrm{~kJ} / \mathrm{kg}$ IBW per d (30 kcal/kg IBW per d) (HR 1.94; $95 \%$ CI 1.12, 3.36) or $\geq 167 \cdot 4 \mathrm{~kJ} / \mathrm{kg}$ IBW per d ( $40 \mathrm{kcal} / \mathrm{kg}$ IBW per d) (HR $2 \cdot 39$; $95 \%$ CI $1 \cdot 14,5 \cdot 03$ ) (Table 3 ).

There was a similar trend in the relationship between DEI by ABW and all-cause or CVD mortality (online Supplementary Fig. S2). Moreover, DEI normalised to IBW calculated from BMI showed the similar relationship with mortality (online Supplementary Fig. S3). Further adjustment for DPI did not substantially change the results (online Supplementary Table S1).

\section{Stratified analyses by potential effect modifiers}

Stratified analyses were performed by age, sex, diabetes, history of CVD, CRP, TC and BMI. The lowest risk of mortality was found in patients with DEI at 125.5 to $<167.4 \mathrm{~kJ} / \mathrm{kg}$ IBW per d 
Table 1. Baseline characteristics of the maintenance haemodialysis patients*

(Means and standard deviations; medians and interquartile ranges (IQR); numbers and percentages)

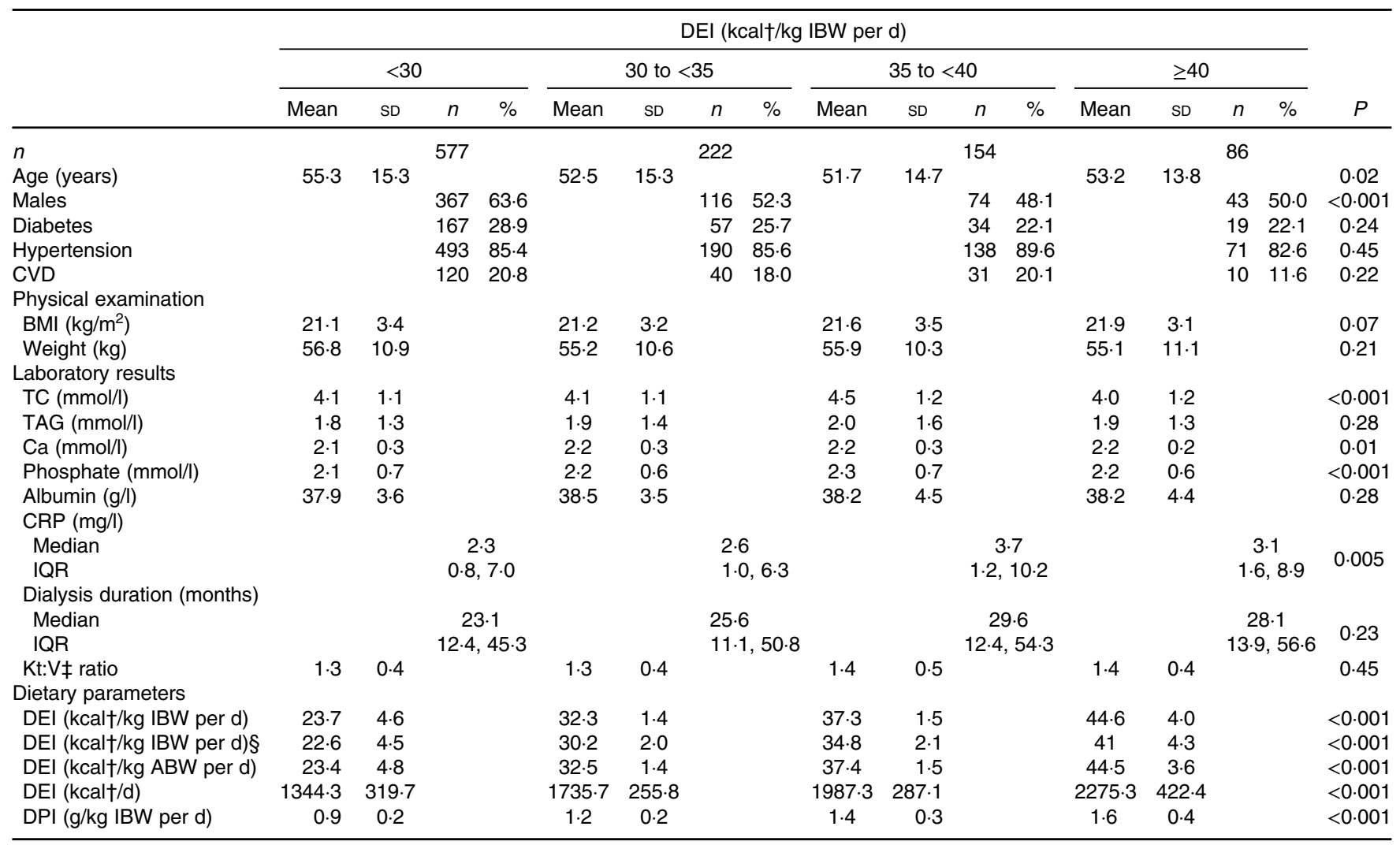

DEI, dietary energy intake; IBW, ideal body weight; TC, total cholesterol; CRP, C-reactive protein; ABW, actual body weight; DPI, dietary protein intake.

* Continuous variables are expressed as means and standard deviations or medians and 25th-75th percentiles; and categorical variables are given as $n$ and \%.

† To convert kcal to kJ, multiply by $4 \cdot 184$.

$\ddagger \mathrm{Kt} / \mathrm{V}, \mathrm{Kt}$ showed effective urea clearance and duration of dialysis, and $\mathrm{V}$ represents the volume of distribution of urea in the body, calculated as $\mathrm{Kt} / \mathrm{V}=-\mathrm{In}$ (post-BUN/pre-

BUN $-0.008 \times t)+(4-3.5 \times$ post-BUN/pre-BUN $) \times$ UF/post-weight, where $t$ is the effective dialysis time, BUN is serum blood urea nitrogen and UF is ultrafiltration.

$\S$ Ideal body weight was defined as a BMI of $22 \mathrm{~kg} / \mathrm{m}^{2}$.

(a)

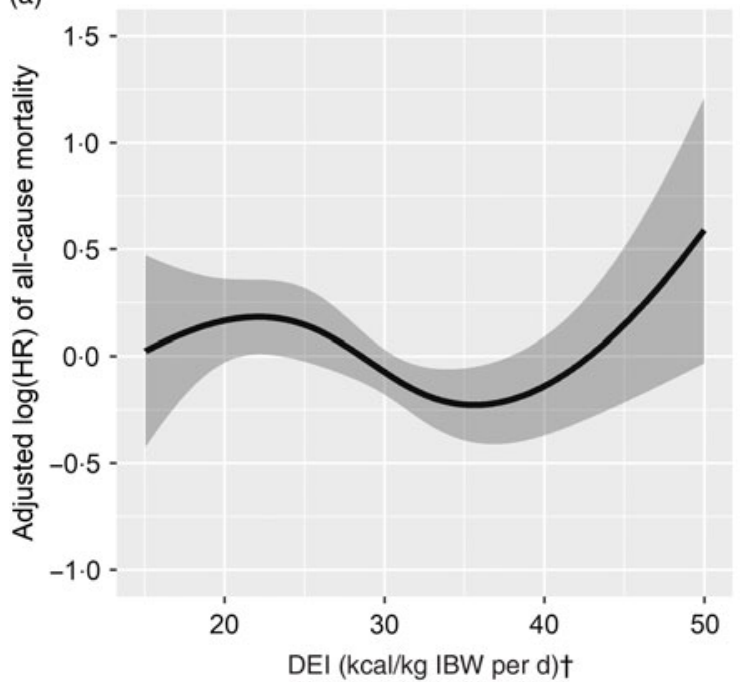

(b)

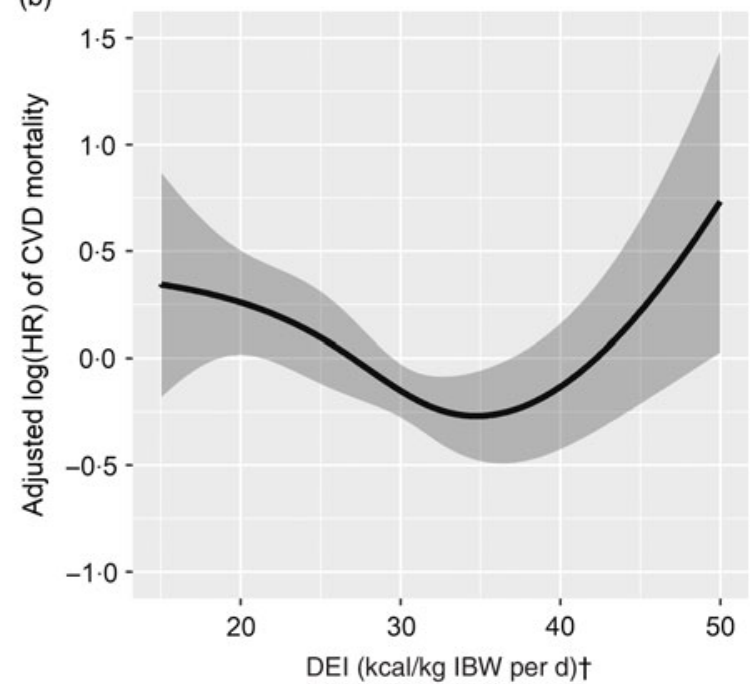

Fig. 1. Association between dietary energy intake (DEI) normalised to ideal body weight (IBW) and risk for all-cause mortality (a) and CVD-related mortality (b) ${ }^{\star}$. HR, hazard ratio. * Adjusted for dialysis centre, age, sex, smoking, alcohol use, physical activity, BMI, albumin, TAG, total cholesterol, C-reactive protein, calcium, phosphate, $\mathrm{Hb}$, dialysis vintage, Kt/V, systolic blood pressure, diabetes and history of CVD. $\dagger$ To convert kcal to kJ, multiply by 4.184. 
Table 2. Threshold effect analyses of dietary energy intake (DEI) levels on the risk of all-cause mortality and CVD mortality using two piecewise regression models

(Numbers and percentages; hazard ratios (HR) and $95 \%$ confidence intervals)

\begin{tabular}{|c|c|c|c|c|c|c|c|c|c|c|c|}
\hline \multirow[b]{2}{*}{ DEI $\left(\mathrm{kcal}^{*} / \mathrm{kg}\right.$ IBW per d) } & \multirow[b]{2}{*}{$\begin{array}{l}\text { No. of events } \\
(n)\end{array}$} & \multirow[b]{2}{*}{$\%$} & \multicolumn{3}{|c|}{ Crude } & \multirow[b]{2}{*}{$\begin{array}{c}\text { DEI } \\
\left(\mathrm{kcal}^{*} / \mathrm{kg} \mathrm{IBW} \text { per d) }\right.\end{array}$} & \multirow[b]{2}{*}{$\begin{array}{l}\text { No. of events } \\
(n)\end{array}$} & \multirow[b]{2}{*}{$\%$} & \multicolumn{3}{|c|}{ Adjusted $†$} \\
\hline & & & $\mathrm{HR}$ & $95 \% \mathrm{Cl}$ & $P$ & & & & $\mathrm{HR}$ & $95 \% \mathrm{Cl}$ & $P$ \\
\hline \multicolumn{12}{|l|}{ All-cause mortality } \\
\hline$<42 \cdot 8$ & 219 & $22 \cdot 2$ & 0.98 & $0.97,1.00$ & 0.084 & $<40$ & 213 & $22 \cdot 4$ & 0.98 & $0.96,1.00$ & 0.027 \\
\hline$\geq 42 \cdot 8$ & 11 & 20.8 & 1.09 & $0.96,1 \cdot 19$ & 0.077 & $\geqslant 40$ & 17 & $19 \cdot 8$ & $1 \cdot 12$ & $1.04,1.20$ & 0.002 \\
\hline \multicolumn{12}{|l|}{ CVD-related mortality } \\
\hline$<33.9$ & 105 & $13 \cdot 8$ & 0.96 & $0.94,0.99$ & 0.013 & $<36.5$ & 115 & 13.4 & 0.96 & $0.93,0.99$ & 0.006 \\
\hline$\geq 33.9$ & 35 & $12 \cdot 5$ & 1.05 & $1 \cdot 00,1 \cdot 11$ & 0.072 & $\geqslant 36.5$ & 25 & $13 \cdot 8$ & $1 \cdot 11$ & $1.04,1 \cdot 18$ & 0.002 \\
\hline
\end{tabular}

IBW, ideal body weight.

* To convert kcal to $\mathrm{kJ}$, multiply by $4 \cdot 184$

† Adjusted for dialysis centre, age, sex, smoking, alcohol use, physical activity, BMI, albumin, TAG, total cholesterol, C-reactive protein, Ca, phosphate, Hb, dialysis vintage, Kt/V, systolic blood pressure, diabetes and history of CVD.

Table 3. Univariate and multi-variate Cox regression models of all-cause mortality and CVD-related mortality for dietary energy intake (DEI) groups (Numbers and percentages; hazard ratios (HR) and $95 \%$ confidence intervals)

\begin{tabular}{|c|c|c|c|c|c|c|c|c|}
\hline \multirow[b]{2}{*}{ DEI (kcal*/kg IBW per d) } & \multirow[b]{2}{*}{ No. of events $(n)$} & \multirow[b]{2}{*}{$\%$} & \multicolumn{3}{|c|}{ Crude } & \multicolumn{3}{|c|}{ Adjusted $†$} \\
\hline & & & $\mathrm{HR}$ & $95 \% \mathrm{Cl}$ & $P$ & $\mathrm{HR}$ & $95 \% \mathrm{Cl}$ & $P$ \\
\hline \multicolumn{9}{|l|}{ All-cause mortality } \\
\hline \multicolumn{9}{|l|}{ Categories } \\
\hline$<30$ & 146 & $25 \cdot 3$ & $1 \cdot 31$ & $0.88,1.95$ & 0.187 & 1.85 & $1 \cdot 20,2 \cdot 85$ & 0.005 \\
\hline $30-35$ & 38 & $17 \cdot 1$ & 0.88 & $0.54,1.42$ & 0.591 & $1 \cdot 31$ & $0.79,2 \cdot 17$ & 0.301 \\
\hline $35-40$ & 29 & $18 \cdot 8$ & $1 \cdot 0$ & Ref & - & 1.0 & Ref & - \\
\hline$\geqslant 40$ & 17 & $19 \cdot 8$ & $1 \cdot 12$ & $0.61,2.03$ & 0.719 & 1.83 & $0.99,3.40$ & 0.056 \\
\hline \multicolumn{9}{|l|}{ Categories } \\
\hline$<30$ & 146 & $25 \cdot 3$ & 1.41 & $1.06,1.89$ & 0.019 & 1.59 & $1 \cdot 17,2 \cdot 16$ & 0.003 \\
\hline $30-40$ & 67 & $17 \cdot 8$ & $1 \cdot 0$ & Ref & - & 1.0 & Ref & - \\
\hline$\geq 40$ & 17 & $19 \cdot 8$ & $1 \cdot 21$ & $0.71,2.05$ & 0.491 & 1.58 & $0.92,2.73$ & 0.099 \\
\hline \multicolumn{9}{|l|}{ CVD-related mortality } \\
\hline \multicolumn{9}{|l|}{ Categories } \\
\hline$<30$ & 92 & $15 \cdot 9$ & $1 \cdot 34$ & $0.81,2 \cdot 23$ & 0.253 & 1.94 & $1 \cdot 12,3 \cdot 36$ & 0.018 \\
\hline $30-35$ & 18 & $7 \cdot 7$ & 0.64 & $0.33,1.24$ & 0.182 & 0.97 & $0.49,1.93$ & 0.931 \\
\hline $35-40$ & 17 & $11 \cdot 7$ & $1 \cdot 0$ & Ref & - & 1.0 & Ref & - \\
\hline$\geq 40$ & 13 & $15 \cdot 1$ & $1 \cdot 38$ & $0 \cdot 67,2 \cdot 81$ & 0.381 & $2 \cdot 39$ & $1.14,5.03$ & 0.021 \\
\hline \multicolumn{9}{|l|}{ Categories } \\
\hline$<30$ & 92 & $15 \cdot 9$ & 1.72 & $1 \cdot 16,2.53$ & 0.007 & 1.97 & $1.30,2.99$ & 0.001 \\
\hline $30-40$ & 35 & $9 \cdot 3$ & $1 \cdot 0$ & Ref & - & 1.0 & Ref & - \\
\hline$\geq 40$ & 13 & $15 \cdot 1$ & 1.76 & $0.93,3.32$ & 0.083 & 2.43 & $1.26,4.69$ & 0.008 \\
\hline
\end{tabular}

IBW, ideal body weight; Ref, reference.

* To convert kcal to kJ, multiply by $4 \cdot 184$.

† Adjusted for dialysis centre, age, sex, smoking, alcohol use, physical activity, BMI, albumin, TAG, total cholesterol, C-reactive protein, Ca, phosphate, Hb, dialysis vintage, $\mathrm{Kt} / \mathrm{V}$, systolic blood pressure, diabetes and history of CVD.

( 30 to $<40 \mathrm{kcal} / \mathrm{kg}$ IBW per $\mathrm{d}$ ) in all the sub-groups. There were no significant interactions in any of the sub-groups ( $P$ for interaction $>0.05$ for all comparisons; Fig. 2).

\section{Discussion}

Our study is the first to demonstrate a U-shaped association between DEI and all-cause or CVD mortality in MHD patients. Participants with a DEI at 146.4 to $<167.4 \mathrm{~kJ} / \mathrm{kg}$ IBW per d (35 to $<40 \mathrm{kcal} / \mathrm{kg}$ IBW per d) had the lowest risk of all-cause and CVD mortality.

Haemodialysis patients are at increased risk of energy deficiency for several reasons, including inadequate energy intake, inflammation and multiple co-morbidities, metabolic and hormonal derangements, haemodialysis-associated catabolism and increased resting energy expenditure ${ }^{(6,27-30)}$. A previous retrospective study including 344 incident haemodialysis patients found that energy intake lower than $104.6 \mathrm{~kJ} / \mathrm{kg}$ per $\mathrm{d}$ was related to worse survival ${ }^{(23)}$. Another retrospective observational study also reported that lower energy intake $(<104.6 \mathrm{~kJ} / \mathrm{kg}$ per d) was associated with all-cause mortality among 144 patients on $\mathrm{MHD}^{(31)}$. Our findings are in agreement with these last two retrospective studies with small sample size, for we also found that DEI levels were inversely associated with all-cause mortality in participants with DEI $<167 \cdot 4 \mathrm{~kJ} / \mathrm{kg}$ IBW per $\mathrm{d}$ ( $40 \mathrm{kcal} / \mathrm{kg}$ IBW per $\mathrm{d}$ ). The mechanisms linking lower energy intake and the risk of mortality are still unclear. When DEI is deficient, body fat and muscle mass are depleted to maintain BMR and protein stores cannot be able to well preserved ${ }^{(6,32)}$. In addition, pro-inflammatory cytokines, such as IL- 6 or TNF- $\alpha$, are higher in MHD patients with reduced nutrient intake ${ }^{(33-36)}$. 
(a)

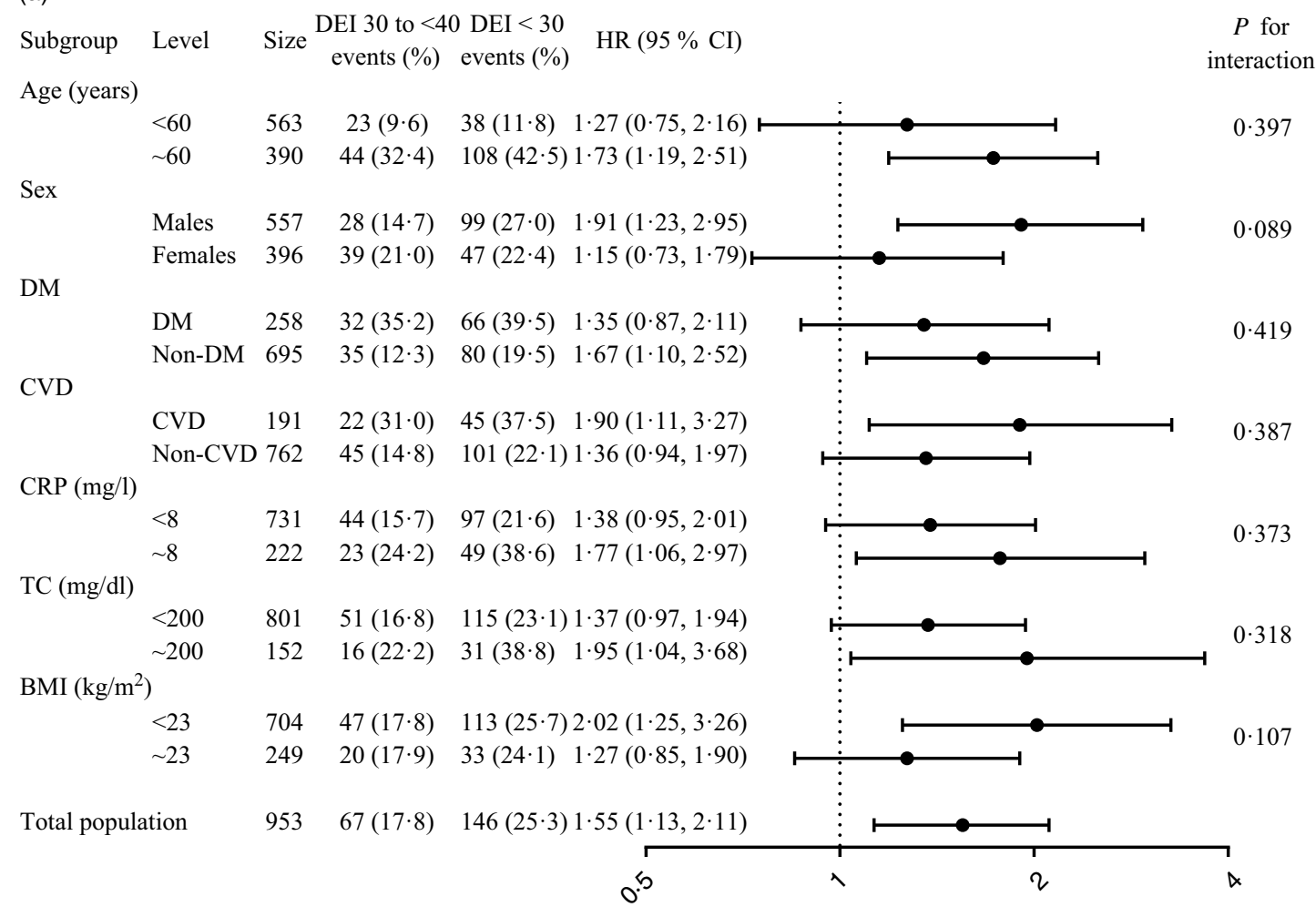

(b)

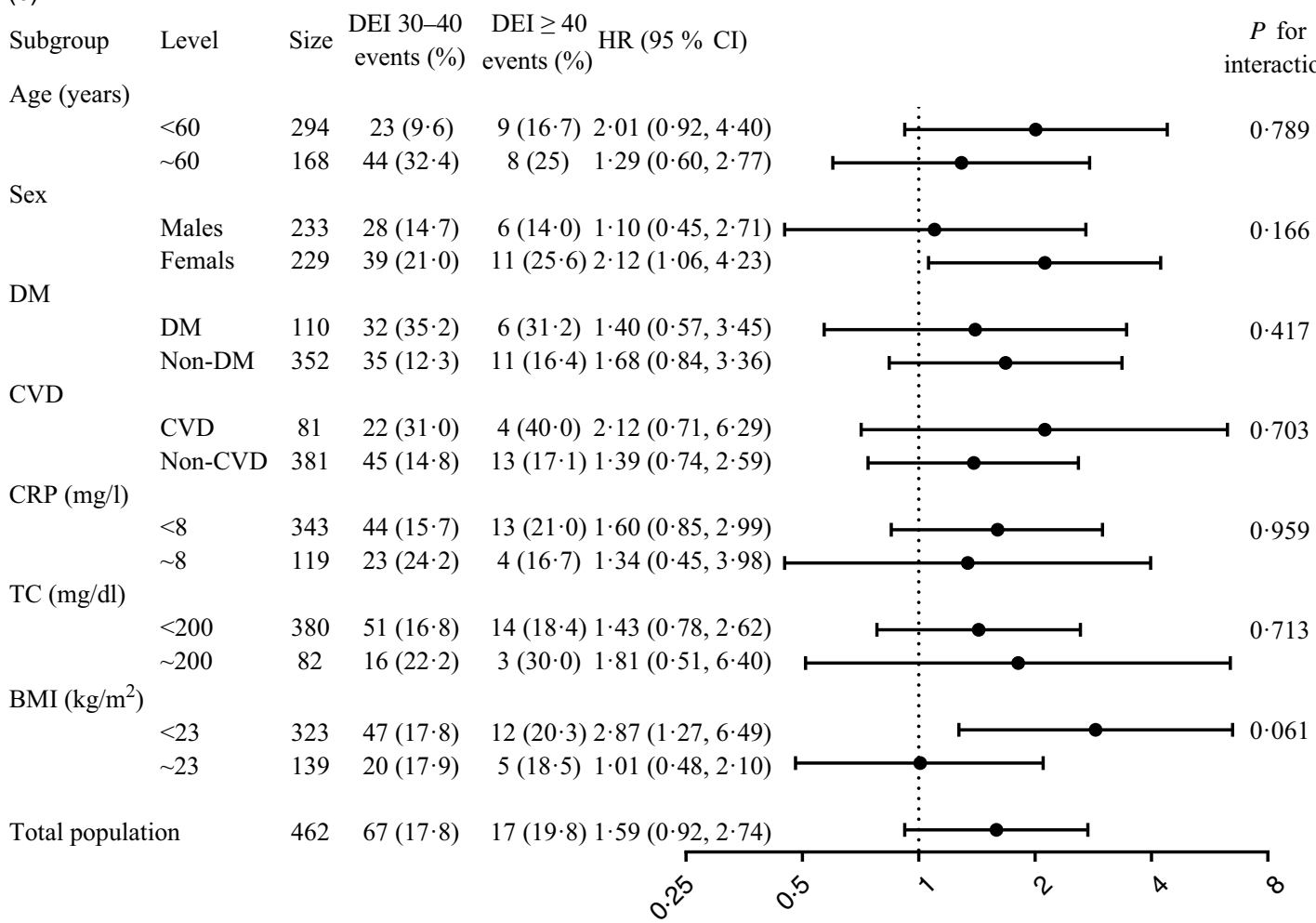

Fig. 2. Sub-group analysis of the relationship of dietary energy intake (DEI) ((a) $<30 \mathrm{v}$. 30 to $<40 \mathrm{kcal} / \mathrm{kg}$ IBW per d and (b) $\geq 40 \mathrm{v}$. 30 to $<40 \mathrm{kcal} / \mathrm{kg}$ IBW per d) with allcause mortality*. DM, diabetes mellitus; HR, hazard ratio; IBW, ideal body weight; TC, total cholesterol. * Adjusted for dialysis centre, age, sex, smoking, alcohol use, physical activity, BMI, albumin, TAG, total cholesterol, C-reactive protein, calcium, phosphate, $\mathrm{Hb}$, dialysis vintage, Kt/V, systolic blood pressure, diabetes and history of CVD. To convert kcal to $\mathrm{kJ}$, multiply by $4 \cdot 184$. To convert cholesterol in $\mathrm{mg} / \mathrm{dl}$ to $\mathrm{mmol} / \mathrm{l}$, multiply by 0.0259 . 
Loss of muscle and fat stores and inflammation may increase the risk of all-cause mortality. Moreover, patients with low energy intake might also have a higher prevalence of latent chronic disease ${ }^{(37)}$.

Our study had a relatively higher DEI compared with some studies. In our study, the mean and standard deviation DEI were $121 \cdot 8$ (sD 34.7) kJ/kg of ABW per d and 122.6 (sD 33.1) kJ/kg IBW per $\mathrm{d}$. In comparison, the mean DEI by $\mathrm{ABW}$ in haemodialysis patients was $95 \cdot 8$ (SD 35.1) $\mathrm{kJ} / \mathrm{kg}$ per $\mathrm{d}$ in the Haemodialysis (HEMO) Study cohort ${ }^{(38)}, 107.9 \mathrm{~kJ} / \mathrm{kg}$ per d in a Korean cohort ${ }^{(31)}$ and $109.6 \mathrm{~kJ} / \mathrm{kg}$ per $\mathrm{d}$ in a Brazilian cohort ${ }^{(23)}$. The differences in mean DEI across these different studies may be due to several reasons. First, dietary habits vary greatly across different countries and cultures. Second, the nutritional status of a population is known to improve with its economic development; the living standards for these populations may have improved considerably since each study was conducted. The HEMO study ${ }^{(38)}$ was conducted between May 1995 and March 1997, the study from Korea ${ }^{(31)}$ was conducted during April 2006 and the study from Brazil ${ }^{(23)}$ was conducted from January 1992 to December 2002. By contrast, our study was conducted more recently, from January 2014 to December 2015. Third, each study used a different method to assess DEI thereby potentially over or under estimating the true energy intake. DEI in the HEMO study was assessed using a 2-d dietary intake diary on one dialysis day and one non-dialysis day and was recorded by patients. However, in our study, DEI was assessed through face-to-face or telephone interview by trained staff on two non-dialysis days and one dialysis day. Fourth, at each follow-up visit, all patients in the present study received information on how to improve their protein and energy intake and may be a major contributor to the relatively high DEI observed in our study. Still, some studies observed similar results compared with our study. In a French study, Chauveau et al. found results with a DEI of $124.7 \mathrm{~kJ} / \mathrm{kg}$ per $\mathrm{d}^{(39)}$. On the other hand, Arslan and Kiziltan assessed a higher DEI of $143.1 \mathrm{~kJ} / \mathrm{kg}$ per $\mathrm{d}$ in ninety-three MHD patients ${ }^{(40)}$.

The relatively high DEI level and large sample size of the present study offer an exceptional opportunity to examine the relationship of higher DEI levels with all-cause and CVD mortality in MHD patients. Our study further indicated that all-cause mortality risk increased significantly with the increase of DEI in participants with DEI $\geq 167.4 \mathrm{~kJ} / \mathrm{kg}$ IBW per d $(40 \mathrm{kcal} / \mathrm{kg}$ IBW per $\mathrm{d}$ ). Consistently, previous studies reported that high energy intake was associated with increased risks of cancer, incident diabetes, all-cause mortality and CVD mortality in general populations ${ }^{(41-43)}$. Iff et al. ${ }^{(44)}$ found that higher relative energy intake increases mortality in patients with estimated glomerular filtration rate $<60 \mathrm{ml} / \mathrm{min}$ per $1.73 \mathrm{~m}^{2}$. The biological mechanisms linking higher DEI to mortality risk are not well known. It has been suggested that excessive energy exposure may increase oxidative stress, leading to diminished mitochondrial function, decreased ATP productive capacity, cell death and multiple organ failure ${ }^{(45)}$. However, more studies are needed to further investigate our findings and examine the underlying mechanisms.

Due to the exclusion of patients with acute infection, CRP was at a relatively low level in the present study. Furthermore, our study showed that patients with higher DEI tended to had higher CRP levels in the present study. At same time, participants with higher DEI also had higher TC levels and there was a positive association between CRP and TC $(P=0.038)$. It has been reported that cholesterol accumulation in macrophages and other immune cells may promote inflammatory responses, including augmentation of Toll-like receptor signalling, inflammasome activation and the production of monocytes and neutrophils ${ }^{(46)}$. Although the underlying mechanisms still need to be further investigated in future studies, we speculated that elevated TC associated with higher DEI may partly explain the increased CRP levels in this population. More importantly, the stratified analysis indicated that both TC and CRP levels did not significantly modify the association between DEI and the mortality risk.

Our findings should be interpreted in the context of several limitations. First, the DEI was assessed using the 24-h diet recalls, which was dependent on reporting by patients ${ }^{(10)}$. However, it is one of the most common methods for obtaining dietary intake data as there are no alternatives to calculate accurate nutrient intake $^{(4)}$. To minimise the potential errors, we used extensive quality control procedures and three 24-h diet recalls including one dialysis day and two non-dialysis days to yield more accurate data. More importantly, the automated multiple-pass method approach to 24-h diet recalls that was used in the present study has been validated by a lot of previous studies ${ }^{(14,16,17,47,48)}$. Although the determination of DEI may possible be unreliable in both obese and very thin ${ }^{(49)}$, the exclusion of patients with BMI $<18.5$ or $\geq 30 \mathrm{~kg} / \mathrm{m}^{2}$ did not substantially change our results (online Supplementary Table S2). Second, dietary intake was assessed at only a single time which did not take into consideration the changing pattern of eating and physical behaviour over the follow-up period. Third, this was an observational study. Despite extensive adjustment for known confounders in our analysis, we cannot exclude the possibility that unrecorded factors may explain some of our findings. Fourth, the study was carried out in China. Whether the results can be extrapolated to other populations requires further verification. Therefore, further confirmation of our findings in an independent trial is greatly needed.

In conclusion, our study suggests a U-shaped association between DEI and all-cause or CVD mortality, with a turning point at about 167.4 and $152.7 \mathrm{~kJ} / \mathrm{kg}$ IBW per d (40 and $36.5 \mathrm{kcal} / \mathrm{kg}$ IBW per $\mathrm{d}$ ), respectively, in MHD patients. Our findings provide new insights with respect to the benefit:risk ratio of energy supplementation in MHD patients.

\section{Acknowledgements}

The authors thank the participants, investigators and staff for their contribution to the present study.

The present study was supported by the National Key Technology Support Program of China (grant no. 2015BAI12B00) and the High-level Matching Funds of Nanfang Hospital (2014070).

Dr X. Q. reports grants from the National Natural Science Foundation of China (81730019) and Outstanding Youths 
Development Scheme of Nanfang Hospital, Southern Medical University (2017J009). Dr F. H. reports grants from the Science and Technology Planning Project of Guangzhou and the National Key Research and Development Program.

Research idea and study design: M. L., S. L. Y., Y. M. L. and Y. Y. Y.; data acquisition: S. L. Y., Y. M. L., Y. Y. Y., Y. L., Z. H. L., Y. Z. K., Y. L., Q. W., F. N. L., S. H., A. Q. L. and Q. J. W.; data analysis/interpretation: Y. M. L, Y. Y. Y., Y. Z. K., Y. L., Q. W., F. N. L., S. H., A. Q. L. and Q. J. W.; statistical analysis: Y. Y. Y. and X. H. Q.; supervision or mentorship: M. L. and X. H. Q. Each author contributed important intellectual content during manuscript drafting or revision and accepts accountability for the overall work by ensuring that questions pertaining to the accuracy or integrity of any portion of the work are appropriately investigated and resolved.

There were no conflicts of interest.

\section{Supplementary material}

For supplementary material referred to in this article, please visit https://doi.org/10.1017/S0007114519002861

\section{References}

1. K/DOQI Workgroup (2005) K/DOQI clinical practice guidelines for cardiovascular disease in dialysis patients. $\mathrm{Am} \mathrm{J}$ Kidney Dis 45, S1-S153.

2. Dwyer JT, Cunniff PJ, Maroni BJ, et al. (1998) The hemodialysis pilot study: nutrition program and participant characteristics at baseline. The HEMO Study Group. J Ren Nutr 8, 11-20.

3. Kovesdy CP, Shinaberger CS \& Kalantar-Zadeh K (2010) Epidemiology of dietary nutrient intake in ESRD. Semin Dial 2, 353-358.

4. National Kidney Foundation (2000) KDOQI Clinical Practice Guidelines for Nutrition in Chronic Renal Failure. Am J Kidney Dis 35, s1-s140.

5. Therrien M, Byham-Gray L \& Beto J (2015) A review of dietary intake studies in maintenance dialysis patients. J Ren Nutr $\mathbf{2 5}$, 329-338.

6. Ikizler TA, Cano NJ, Franch H, et al. (2013) Prevention and treatment of protein energy wasting in chronic kidney disease patients: a consensus statement by the International Society of Renal Nutrition and Metabolism. Kidney Int 84, 1096-1107.

7. Chen J, Qin X, Li Y, et al. (2019) Comparison of three nutritional screening tools for predicting mortality in maintenance hemodialysis patients. Nutrition 67-68, 110532.

8. Slomowitz LA, Monteon FJ, Grosvenor M, et al. (1989) Effect of energy intake on nutritional status in maintenance hemodialysis patients. Kidney Int 35, 704-711

9. Fouque D, Vennegoor M, ter Wee P, et al. (2007) EBPG guideline on nutrition. Nephrol Dial Transpl 22, Suppl. 2, S45-S87.

10. Bross R, Noori N, Kovesdy CP, et al. (2010) Dietary assessment of individuals with chronic kidney disease. Semin Dial 23, 359-364.

11. Hebert JR, Hurley TG, Chiriboga DE, et al. (1998) A comparison of selected nutrient intakes derived from three diet assessment methods used in a low-fat maintenance trial. Public Health Nutr 1, 207-214.

12. Subar AF, Kipnis V, Troiano RP, et al. (2003) Using intake biomarkers to evaluate the extent of dietary misreporting in a large sample of adults: the open study. Am J Epidemiol 158, 1-13.
13. Prentice RL, Mossavar-Rahmani Y, Huang Y, et al. (2011) Evaluation and comparison of food records, recalls, and frequencies for energy and protein assessment by using recovery biomarkers. Am J Epidemiol 174, 591-603.

14. Burrows TL, Martin RJ \& Collins CE (2010) A systematic review of the validity of dietary assessment methods in children when compared with the method of doubly labeled water. J Am Diet Assoc 110, 1501-1510.

15. Conway JM, Ingwersen LA, Vinyard BT, et al. (2003) Effectiveness of the US Department of Agriculture 5-step multiple-pass method in assessing food intake in obese and nonobese women. Am J Clin Nutr 77, 1171-1178.

16. Bingham SA, Gill C, Welch A, et al. (1994) Comparison of dietary assessment methods in nutritional epidemiology: weighed records v. $24 \mathrm{~h}$ recalls, food-frequency questionnaires and estimated-diet records. BrJ Nutr 72, 619-643.

17. Conway JM, Ingwersen LA \& Moshfegh AJ (2004) Accuracy of dietary recall using the USDA five-step multiple-pass method in men: an observational validation study. J Am Diet Assoc 104, 595-603.

18. Wang Y, Li X, Qin X, et al. (2013) Prevalence of hyperhomocysteinaemia and its major determinants in rural Chinese hypertensive patients aged 45-75 years. Br J Nutr 109, $1284-1293$

19. Qin X, Li J, Zhang Y, et al. (2012) Prevalence and associated factors of diabetes and impaired fasting glucose in Chinese hypertensive adults aged 45 to 75 years. PLOS ONE 7, e42538.

20. Shah B, Sucher K \& Hollenbeck CB (2006) Comparison of ideal body weight equations and published height-weight tables with body mass index tables for healthy adults in the United States. Nutr Clin Pract 21, 312-319.

21. Rao KV \& Balakrishna N (1995) Feasibility of Broka's index for the nutritional status of adults. Indian J Med Res 102, 173-178.

22. Watanabe D, Machida S, Matsumoto N, et al. (2018) Age modifies the association of dietary protein intake with all-cause mortality in patients with chronic kidney disease. Nutrients 10, 1744

23. Araújo IC, Kamimura MA, Draibe SA, et al. (2006) Nutritional parameters and mortality in incident hemodialysis patients. J Ren Nutr 16, 27-35.

24. Zimmermann J, Herrlinger S, Pruy A, et al. (1999) Inflammation enhances cardiovascular risk and mortality in hemodialysis patients. Kidney Int 55, 648-658.

25. Sarnak MJ, Bloom R, Muntner P, et al. (2015) KDOQI US commentary on the 2013 KDIGO Clinical Practice Guideline for Lipid Management in CKD. Am J Kidney Dis 65, 354-366.

26. WHO Expert Consultation (2004) Appropriate body-mass index for Asian populations and its implications for policy and intervention strategies. Lancet 363, 157-163.

27. Ikizler TA, Wingard RL, Sun M, et al. (1996) Increased energy expenditure in hemodialysis patients. J Am Soc Nephrol 7 , 2646-2653.

28. Wang AY, Sanderson J, Sea MM, et al. (2003) Important factors other than dialysis adequacy associated with inadequate dietary protein and energy intakes in patients receiving maintenance peritoneal dialysis. Am J Clin Nutr 77, 834-841.

29. Parker TF, Wingard RL, Husni L, et al. (1996) Effect of the membrane biocompatibility on nutritional parameters in chronic hemodialysis patients. Kidney Int 49, 551-556.

30. Pupim LB \& Ikizler TA (2003) Uremic malnutrition: new insights into an old problem. Semin Dial 16, 224-232.

31. Kang SS, Chang JW \& Park Y (2017) Nutritional status predicts 10 -year mortality in patients with end-stage renal disease on hemodialysis. Nutrients 9, 399.

32. Fouque D, Kalantar-Zadeh K, Kopple J, et al. (2008) A proposed nomenclature and diagnostic criteria for protein-energy 
wasting in acute and chronic kidney disease. Kidney Int $\mathbf{7 3}$, 391-398.

33. Qureshi AR, Alvestrand A, Divino-Filho JC, et al. (2002) Inflammation, malnutrition, and cardiac disease as predictors of mortality in hemodialysis patients. J Am Soc Nephrol 13, Suppl. 1, S28-S36.

34. Katona P \& Katona-Apte J (2008) The interaction between nutrition and infection. Clin Infect Dis 46, 1582-1588.

35. Fouque D, Pelletier S, Mafra D, et al. (2011) Nutrition and chronic kidney disease. Kidney Int 80, 348-357.

36. Kalantar-Zadeh K, Block G, McAllister CJ, et al. (2004) Appetite and inflammation, nutrition, anemia, and clinical outcome in hemodialysis patients. Am J Clin Nutr 80, 299-307.

37. Leosdottir M, Nilsson P, Nilsson JA, et al. (2004) The association between total energy intake and early mortality: data from the Malmo Diet and Cancer Study. J Intern Med 256, 499-509.

38. Rocco MV, Paranandi L, Burrowes JD, et al. (2002) Nutritional status in the HEMO Study cohort at baseline. Hemodialysis. Am J Kidney Dis 39, 245-256.

39. Chauveau P, Grigaut E, Kolko A, et al. (2007) Evaluation of nutritional status in patients with kidney disease: usefulness of dietary recall. J Ren Nutr 17, 88-92.

40. Arslan Y \& Kiziltan G (2010) Nutrition-related cardiovascular risk factors in hemodialysis patients. J Ren Nutr 20, 185-192.

41. Silvera SA, Jain M, Howe GR, et al. (2006) Energy balance and breast cancer risk: a prospective cohort study. Breast Cancer Res Treat 97, 97-106.
42. Nagai M, Ohkubo T, Miura K, et al. (2016) Association of total energy intake with 29-year mortality in the Japanese: NIPPON DATA80. J Atheroscler Thromb 23, 339-354.

43. Hingle MD, Wertheim BC, Neuhouser ML, et al. (2017) Association between dietary energy density and incident type 2 diabetes in the women's health initiative. J Acad Nutr Diet 117, 778-785.

44. Iff S, Wong G, Webster AC, et al. (2014) Relative energy balance, CKD, and risk of cardiovascular and all-cause mortality. Am J Kidney Dis 63, 437-445.

45. Cano NJ, Fouque D, Roth H, et al. (2007) Intradialytic parenteral nutrition does not improve survival in malnourished hemodialysis patients: a 2-year multicenter, prospective, randomized study. J Am Soc Nephrol 18, 2583-2591.

46. Tall AR \& Yvan-Charvet L (2015) Cholesterol, inflammation and innate immunity. Nat Rev Immunol 15, 104-116.

47. Johnson RK, Driscoll P \& Goran MI (1996) Comparison of multiple-pass 24-hour recall estimates of energy intake with total energy expenditure determined by the doubly labeled water method in young children. J Am Diet Assoc 96, 1140-1144.

48. Sawaya AL, Tucker K, Tsay R, et al. (1996) Evaluation of four methods for determining energy intake in young and older women: comparison with doubly labeled water measurements of total energy expenditure. Am J Clin Nutr 63, 491-499.

49. Poslusna K, Ruprich J, de Vries JH, et al. (2009) Misreporting of energy and micronutrient intake estimated by food records and 24 hour recalls, control and adjustment methods in practice. $\mathrm{BrJ}$ Nutr 101, Suppl. 2, S73-S85. 